\title{
Willful Ignorance as Formative Epistemic Injustice
}

\author{
A. C. Nikolaidis \\ The Obio State University
}

Willful ignorance has been extensively theorized in a variety of disciplines including philosophy, critical theory, and law. The voluminous literature portrays the concept's great nuance as well as the difficulty of pinning down its precise contours. While such work has significantly improved our understanding of the mechanisms by which social injustice is sustained and the reasons why many refuse to acknowledge it and/or address it, I contend that viewing willful ignorance through an educational lens can advance our understanding even more. This involves framing willful ignorance as an essentially educational form of injustice, namely, formative epistemic injustice. The argument is structured as follows: Section I provides an overview of willful ignorance scholarship, Section II discusses conceptual limitations of willful ignorance, Section III provides an example to illustrate said limitations, Section IV defines formative epistemic injustice, Section V distinguishes between two levels of formative epistemic injustice, and Section VI concludes by recapitulating the benefits of conceptualizing willful ignorance as formative epistemic injustice.

\section{THE SCOPE OF WILLFUL IGNORANCE}

Multiple accounts of willful ignorance have been advanced over the years. Charles Mills describes willful (or white) ignorance as a pattern of cognitive dysfunctions constructed by dominant groups to ingrain systems of oppression and maintain their social advantages. These cognitive dysfunctions conceal the true nature of the world, especially, though not exclusively, from these same dominant groups. ${ }^{1}$ Extending Mills' account, José Medina connects willful ignorance to epistemic vice, and Gaile Pohlhaus, Jr. describes it as a dominant group's preemptive dismissal of, and refusal to engage with, marginally situated epistemic resources. ${ }^{2}$ Nancy Tuana refers to it as "a systematic process 
of self-deception" which obscures privileged individuals' contributions to the exploitation of marginalized populations. ${ }^{3}$ Kevin Lynch disagrees that willful ignorance involves self-deception as such deception negates its willfulness. Contrary to self-deception, willful ignorance implies that one both suspects that what one does not know and avoids learning is true and evades evidence that could confirm one's suspicion. ${ }^{4}$ For Michele Moody-Adams, willful (or affected) ignorance entails "choosing not to know what one can and should know" about the wrongfulness of one's conduct to preserve one's lifestyle. ${ }^{5} \mathrm{Jan}$ Wieland extends Moody-Adams' account to include cases where not knowing may not be self-interested (i.e., lifestyle preserving) but simply convenient. ${ }^{6}$ Barbara Applebaum goes further than Moody-Adams and Wieland, arguing that willful ignorance entails "needing not to know" how one's actions render them complicit to injustice to preserve their "moral innocence."” Along similar psychological lines, Jennifer Logue describes willful ignorance as an "active force of both psychic and social consequence" that constitutes our very agency as humans. ${ }^{8}$

This brief survey is meant to demonstrate the general disagreement regarding the contours of willful ignorance: whether it includes both intentional and unintentional acts, whether it presupposes at least some knowledge or none, whether it must be self-interested or simply convenient, or whether its nature is primarily cognitive or affective. These conceptual differences carry important implications for how we assign culpability to those who are willfully ignorant. The degree of culpability may differ if one reserves the term for intentional as opposed to unintentional or even unconscious acts, ${ }^{9}$ the scope of culpability might change depending on whether willful ignorance is simply viewed as a personal deficiency or a socially induced pattern, ${ }^{10}$ and ascription of culpability may vary based on the reasonableness of acquiring knowledge under particular circumstances. ${ }^{11}$

\section{THE LIMITS OF WILLFUL IGNORANCE}

These considerations are important and the scholarly debates that address them very generative. However, when it comes to willful ignorance 
as a mechanism of perpetuating social injustice, the concept seems unable to capture an important educational facet of the problem. The limitation stems from the very use of the term "willful," which denotes intentionality. Given the assumption of intentionality, willful ignorance implicitly assigns each person sole responsibility for theirignorance and thereby for any unjust actions they perform out of ignorance. Yet, as Mills argues, willful ignorance that perpetuates social injustice is structural in nature and manifests in the form of a "group-based cognitive handicap"- white ignorance, male ignorance, and the like-which affects privileged groups and individuals vis-à-vis their social situatedness. ${ }^{12}$ The concept's very structural nature then suggests that privileged groups "may have inculcated a pattern of belief-forming practices that created the effect of systematic ignorance," which further suggests that members of privileged groups have been brought up - through some kind of formal or informal education - to internalize ignorance-inducing "belief-forming practices." ${ }^{13}$ As Mills puts it, "one has to learn to see the world wrongly." ${ }^{14}$ It follows that willful ignorance may be too individualistic to capture this structural nature and may conceal both the lack of choice regarding whether to remain ignorant or not that persons often experience as a result of their formal or informal education and our collective responsibility qua educators, whether formal or informal, in the perpetuation of this socially induced pattern.

One may object here that "willful" need not denote intentionality but rather, in Linda Martín Alcoff's words, "a positive interest" to create and sustain faulty epistemic practices. ${ }^{15}$ Applebaum endorses this view and argues that white ignorance can be considered willful because it "benefits the person or the social group the person is a member of" and, thus, dominant groups "have a vested interest in not knowing." "This is certainly true with regard to white (and other structural forms of) ignorance. Yet even such an account conceals the potential educational and/or material harms of such ignorance to willfully ignorant individuals or groups. This is not to say that these harms outweigh the benefits, though as I show they may, nor that they are more important than harms inflicted on marginalized populations by willfully ignorant individuals or groups. Rather, I argue, the harms to those who are willfully ignorant deserve 
greater attention because they are (1) educational wrongs in their own right and (2) causally antecedent to wrongs perpetrated by the willfully ignorant.

\section{DYING OF WHITENESS}

To illustrate the limitations of willful ignorance, I refer to a recent book by Jonathan Metzl. Metzl discusses how poor Midwestern and Southern whites have embraced an ideology of whiteness that compels them to oppose policy reforms that they believe would benefit marginalized (particularly nonwhite) populations. ${ }^{17}$ The term white ignorance, an example of racially motivated willful ignorance, aptly describes this state of affairs:

Poor whites' conduct is, at least partly, ignorant because

(1) it is fair to assume that they are, at the very least, not fully knowledgeable of the effects or harmfulness of their conduct on marginalized communities. Had they known the full extent of racial injustice and the suffering it causes they may have been more sensitive to the plight of marginalized communities.

Moreover, poor whites' ignorance is willful because either

(2) they suspect or even expect, by the very nature of the policies they oppose, that their actions deny certain groups needed support and so intentionally avoid verifying whether this is true to continue pursuing the same course of action, or,

$\left(2^{\prime}\right)$ they are completely unaware of the significance of their actions but are benefitting from this ignorance symbolically (by preserving their social status as whites) and/or materially (by preserving their economic privileges). Furthermore, they avoid facing an inconvenient truth that would challenge their very sense of identity.

Statement (1) satisfies the condition of ignorance and statements (2) and $\left(2^{\prime}\right)$ satisfy the condition of willfulness. In that sense, the poor whites that 
Metzl talks of are willfully ignorant-i.e., they exhibit white ignorance. ${ }^{18}$

Yet Metzl shows that white ignorance prompts poor whites to support policies-decreased gun control, rollback of the Affordable Care Act, and aggressive privatization of education - that conflict with their own interests by severely reducing their life-expectancy and prospects. This suggests that the benefits of white supremacist ideology for poor whites, though certainly considerable, may be exaggerated. No reasonable person would consider these benefits to be worth reducing one's quality of life, compromising the well-being and health of oneself or one's family, diminishing one's ability to access opportunities and flourish, or paying the ultimate cost of one's life or the life of a family member. Nonetheless, many poor whites are willing to pay these costs to stay true to their erroneous worldview. Metzl's examples then not only substantiate the structural nature of willful ignorance as a group-based cognitive dysfunction but also challenge the very assumption that willfully ignorant people have a positive interest in remaining ignorant; viz., that their willful ignorance is advantageous, beneficial, in their interest, or even convenient-unless convenience means exerting minimal cognitive effort.

We see, therefore, that the harms of willful ignorance are sometimes too considerable even for those whose willful ignorance is seemingly self-serving. As Metzl shows, the very white supremacist ideology that poor whites embrace to avoid imagined threats — such as nonwhites who are out to get them or the government taking away their rights - is a more substantive threat to their physical and psychological well-being than the threats they perceive and a significant cause of harm in poor white communities. Metzl shows that poor whites are literally "dying of whiteness," by embracing an ideology that directly conflicts with their self-interests and distorts their self-perceptions. Such ideology depends on cognitive dysfunctions of the form of structural willful ignorance to ensure that its oppressive function remains operational and unchallenged. ${ }^{19}$ It depends on the wide dissemination of an erroneous worldview and, relatedly, on people being miseducated and learning to see the world erroneously. More importantly, such ideology depends on people developing a false consciousness which compels them to reject any evidence that belies their erroneous worldview. ${ }^{20}$ 


\section{FORMATIVE EPISTEMIC INJUSTICE}

Given the pernicious effects of such ignorance-producing ideologies, I argue that their dissemination constitutes an essentially educational form of injustice the harms of which extend beyond education. Conceptualizing willful ignorance as such an injustice, what Christopher Martin calls a formative epistemic injustice, adds nuance to our understanding of willful ignorance. ${ }^{21}$ Formative epistemic injustice highlights the structural nature of ignorance-producing ideologies, their extensive harms, and our collective responsibility for their perpetuation. ${ }^{22}$

As the subcomponents of the term indicate, a formative epistemic injustice is a wrong inflicted on someone in their capacity as a knower which severely obstructs their formative capacities. ${ }^{23}$ In terms designated by epistemic injustice scholars, the harm in one's capacity as a knower, or the epistemic harm, may include: (1) deflation of one's epistemic credibility due to prejudice against one's identity and related inability to transmit knowledge, ${ }^{24}(2)$ marginalization from common epistemic resources and related inability to understand the significance of one's experiences, ${ }^{25}$ (3) inability to communicate one's experiences to dominantly situated knowers and contribute to knowledge production due to epistemic exclusion, ${ }^{26}$ and/or (4) inability to access information to which one is entitled. ${ }^{27}$ The obstruction of one's formative capacities, or the formative harm, comes as a result of the epistemic harm and reduces one's ability to control their self-formation and, thereby, lead a flourishing life. In terms designated by formative justice scholars, the formative harm may include: (1) failure to define one's controlling purposes based on one's dispositions, ${ }^{28}$ (2) failure to regulate one's faculties and cultivate one's capabilities so as to successfully pursue one's purposes, ${ }^{29}$ and/or (3) unwarranted constraint(s) on one's potentialities. ${ }^{30}$ Formative epistemic injustice is distinct from both epistemic injustice and formative injustice in that it focuses on the intersection of the two; the epistemic harm is relevant insofar as it leads to the formative harm and the formative harm is relevant insofar as it emanates from the epistemic harm. Moreover, formative epistemic injustice is essentially educational in that its main considerations are 
knowledge acquisition and self-formation. ${ }^{31}$

To explain the functioning of formative epistemic injustice I return to Metzl's example of white ignorance. The epistemic harm here includes being misinformed about things that one has a strong interest in knowing. For example, poor whites have an interest in knowing that wealthy white elites have historically employed white supremacist ideology to divide the poor across racial lines and suppress unified revolt against economic exploitation. The epistemic harm also includes the exclusion of marginally situated knowers from dominant epistemic resources. Although this epistemic harm primarily affects people of color by epistemically erasing their experiences, it also denies poor whites adequate resources for comprehending their own racialized experiences- the meaning of their whiteness. These epistemic harms are engendered by socially induced patterns of systematic epistemic marginalization and exclusion and are thus structural in nature. As such, no single person is responsible for them-though some hold greater responsibility—and we all to some degree, wittingly or unwittingly, contribute to their perpetuation and, thereby, to the dissemination of faulty epistemic resources through institutional or interpersonal interactions. ${ }^{32}$

The epistemic harms, in turn, lead to formative harms; they interfere with poor whites' capacity for self-formation. Poor whites' cognitive deficits obstruct the development of their cognitive and moral capacities, constraining their potentialities and ability to flourish. This occurs as poor whites come to identify with ideas of white moral and intellectual superiority, ideas that are embedded in their faulty epistemic resources and define their very selfhood. Cognitive deficit (epistemic harm) begets false consciousness (formative harm) and precludes choices that would have been more beneficial both for themselves and for others. Their whiteness delimits their actions in ways that, had they been given a real opportunity to control their self-formation, could have been prevented. ${ }^{33} \mathrm{It}$ is in this sense that poor whites are experiencing an essentially educational form of injustice. I must note that being disadvantaged on the basis of class is not the reason why poor whites experience formative epistemic injustice, though it certainly exacerbates the degree of injustice they experience. Privileged individuals or groups—even those privileged with regard 
to all aspects of their identity who are most responsible for social injustice- - are not immune to experiencing formative epistemic injustice. The harm for them, however, pertains more so to the formation of their critical and moral capacities than to their capacities for economic sufficiency and good health. Their miseducation may deny them a viable opportunity to lead a critically aware and conscientious life and to avoid acting unjustly and inflicting suffering on others.

\section{PRIMARY AND SECONDARY FORMATIVE}

\section{EPISTEMIC INJUSTICE}

Formative epistemic injustice is a wrong in itself but may also lead to practical harms that extend beyond education, such as diminished quality of life and life-prospects in general. Insofar as practical harms emanate from ignorance-producing ideologies, and can be avoided by disrupting their dissemination, I argue that these harms constitute a further manifestation of formative epistemic injustice. We can thus distinguish between two levels of harm in formative epistemic injustice.

At the primary level, formative epistemic injustice involves the dissemination and inculcation of ignorance-producing ideologies which create cognitive deficits, foster false consciousness, and perpetuate willful ignorance. Victims of primary formative epistemic injustice can be both marginalized and privileged groups or individuals, though, as has been suggested by feminist and critical race scholars, the more privilege one has the more susceptible they will be to primary formative epistemic injustice. ${ }^{34}$ Social disadvantage protects one from experiencing primary formative epistemic injustice by affording one "experience rich" epistemic resources and thus important insight that disrupts ignorance-producing ideologies. ${ }^{35}$ Of course, no one is completely immune to this injustice. Finally, primary formative epistemic injustice has exclusively immaterial consequences_-viz., its harms are epistemic (limiting one's capacity as a knower) and formative (limiting one's capacity for self-formation).

At the secondary level, formative epistemic injustice involves material harms and undeserved material benefits that emanate from ignorance-producing 
ideologies and thus are derivative of primary harms. Though injustice is generally associated with harm rather than with benefit, to the extent that the undeserved benefits to privileged groups are the cause of harms to marginalized groups these benefits are morally equivalent to the harms they beget, and, as such, can also be considered manifestations of secondary formative epistemic injustice. Given that material harms are arguably more severe than immaterial, secondary formative epistemic injustice is more severe than primary. It almost exclusively affects marginalized populations, though, as demonstrated by Metzl, it can also affect groups that are somehow privileged - I doubt that it affects those who are privileged with regard to all aspects of their identity. When it does affect groups that are somehow privileged, the consequences are typically less severe than they are for marginalized groups. Even the presence of partial privilege helps insulate people from the material harms of formative epistemic injustice. For this reason, the more marginalized one is, the more vulnerable they will be to secondary formative epistemic injustice.

Though the same person or group may suffer both primary and secondary formative epistemic injustice-e.g., people of color, women, people with disabilities, the poor, etc.- this need not be the case. In fact, more often than not the victims of primary formative epistemic injustice are different from the victims of secondary. Often the cognitive deficits of privileged individuals are the very reason that marginalized individuals suffer severe material harms. ${ }^{36}$ Yet even these harms are the result of ignorance-producing ideologies which stunt the cognitive and moral formation of their adherents, to the extent that adherents of such ideologies can grasp neither the magnitude and severity of injustice to which marginalized people are subjected nor their complicity in sustaining this injustice and their moral responsibility to remedy it. Were they able to, it is likely that more privileged individuals, though certainly not all, would take reasonable action to discharge their responsibility for social justice. Ignorance-producing ideologies are the causal impetus of the unjust conduct that causes or contributes to severe material harms. Primary formative epistemic injustice is thus antecedent to secondary and secondary derivative of primary. The logical relationship between the two levels of formative epistemic injustice 
suggests that we may best be able to tackle its more severe material harms by disrupting its less severe educational harms. Doing so would, of course, be no small feat. It would require both a concerted educational reform effort to disrupt epistemically oppressive structures in formal and informal educational institutions and increasing awareness regarding our individual and collective responsibility for disrupting the formative epistemic injustices that pervade our daily interactions. However, it is worth the effort given education's ability to yield lasting change. Of course, any educational efforts to disrupt primary formative epistemic injustice (and indirectly secondary formative epistemic injustice) ought to be accompanied by direct efforts to disrupt the more urgent material harms of secondary formative epistemic injustice.

\section{CONCLUSION: THE BENEFITS OF FORMATIVE EPISTEMIC INJUSTICE}

While this is merely a cursory overview of formative epistemic injustice, I hope that it demonstrates the merits of conceptualizing willful ignorance in educational terms. To be clear, willful ignorance is a salient concept and sheds light on the social and psychological forces that sustain oppression. Formative epistemic injustice is not meant to replace willful ignorance or diminish its value but to, hopefully, draw attention to its educational implications and add nuance to our understanding of educational responsibility. Before concluding I will recapitulate some of the benefits of conceptualizing willful ignorance as formative epistemic injustice. First, we avoid the ambiguity of willful ignorance. Second, we understand that willful ignorance is at root a structural educational problem. Instead of only focusing on increasing willfully ignorant individuals' awareness, then, we must also initiate large-scale educational reform to address cognitive dysfunctions at a structural level. Moreover, given our collective responsibility for sustaining ignorance-producing ideologies, a shift toward formative epistemic injustice also implies assigning everyone, in their capacity as formal and/or informal educators, additional responsibility for disrupting such ideologies. Third, formative epistemic injustice reveals that willful ignorance is a double injustice: one educational and one material (what I called primary and 
secondary formative epistemic injustice). Finally, formative epistemic injustice reveals that the harms of willful ignorance extend to privileged groups.

This final point is not to intended to divert attention away from the harms experienced by marginalized groups. Those who are marginalized suffer, and have historically suffered, the most and should therefore always be prioritized. However, there is ample work that addresses the harms experienced by marginalized groups as a result of willful ignorance and, to my knowledge, little work that addresses the harms to privileged groups. Addressing these harms is necessary not only because these harms can have severe consequences for privileged groups, but, more importantly, because doing so would mitigate many of the material harms that marginalized groups experience on a regular basis. Focus on the privileged then is warranted primarily, though not exclusively, because of its beneficial effects on the marginalized. Formative epistemic injustice thus enriches our understanding of willful ignorance and expands the scope of available remedies.

1 Charles Mills, The Racial Contract (Ithaca, NY: Cornell University Press, 1997), 17-19; Charles Mills, "White Ignorance," in Race and Epistemologies of Ignorance, eds. Shannon Sullivan and Nancy Tuana (Albany, NY: State University of New York Press, 2007), 13-38.

2 José Medina, The Epistemology of Resistance: Gender and Racial Oppression, Epistemic Injustice, and Resistant Imaginations (New York: Oxford University Press, 2013), 39; Gaile Pohlhaus, Jr, "Relational Knowing and Epistemic Injustice: Toward a Theory of 'Willful Hermeneutical Ignorance'," Hypatia 27, no. 4 (2012): 722. See also Kristie Dotson, "A Cautionary Tale: On Limiting Epistemic Oppression," Frontiers 33, no. 1 (2012): 24-47.

3 Nancy Tuana, “The Speculum of Ignorance: The Women's Health Movement and Epistemologies of Ignorance," Hypatia 21, no. 3 (2006): 11. 4 Kevin Lynch, "Willful Ignorance and Self-Deception," Philosophical Studies 173, no. 2 (2016): 521-522. See also Alexander Sarch, "Willful Ignorance in Law and Morality," Philosophy Compass 13, no. 5 (2018): 6-8. 
5 Michele Moody-Adams, "Culture, Responsibility, and Affected Ignorance," Etbics 104, no. 2 (1994): 296.

6 Jan Willem Wieland, “Willful Ignorance,” Ethical Theory \& Moral Practice 20, no. 1 (2017): 109-111.

7 Barbara Applebaum, "Needing Not to Know: Ignorance, Innocence, Denial, and Discourse," in Philosophy of Education 2015, ed. Eduardo Duarte (Urbana, IL: Philosophy of Education Society, 2015), 451-452.

8 Jennifer Logue, "The Unbelievable Truth and the Dilemmas of Ignorance," in Philosophy of Education 2008, ed. Ronald Glass (Urbana, IL: Philosophy of Education Society, 2008), 55.

9 Willful ignorance, for instance, may be more culpable than culpable ignorance in that the former implies intentional action while the latter mere negligence. See Lynch, "Willful Ignorance and Self-Deception," 508. Moreover, a willfully ignorant act may itself be assigned different degrees of culpability depending on the agent's motivation for remaining ignorant-e.g., whether it was to avoid liability or to avoid facing an inconvenient truth. See David Luban, “Contrived Ignorance," Georgetown Law Journal 87, no. 4 (1999): 967-969. 10 Willful ignorance resulting from personal deficiency would best be addressed using a liability model of responsibility. A socially induced pattern of willful ignorance, on the other hand, would best be addressed using a social connection model of responsibility. This entails assigning responsibility to all those who somehow contribute through their actions to structural injustice. See Iris Marion Young, "Responsibility and Global Justice: A Social Connection Model," Social Philosophy and Policy 23, no. 1 (2006): 115-125. See also Barbara Applebaum, Being White, Being Good: White Complicity, White Moral Responsibility, and Social Justice Pedagogy (Lanham: Rowman \& Littlefield, 2010), chapters 5 and 6 .

11 For instance, while Gideon Rosen suggests that should one receive a poor moral education it is unreasonable to expect them to act in a morally responsible manner, William FitzPatrick argues that one's capabilities and social opportunities for moral knowledge acquisition should determine the reasonableness of any such expectation. See Rosen, "Skepticism about Moral Responsibility," Philosophical Perspectives 18, no. 1 (2004): 304-306; William J. 
FitzPatrick, "Moral Responsibility and Normative Ignorance: Answering a New Skeptical Challenge," Ethics 118, no. 4 (2008): 601-610.

12 Mills, "White Ignorance," 15.

13 Linda Martin Alcoff, "Epistemologies of Ignorance: Three Types," in Race and Epistemologies of Ignorance, eds. Shannon Sullivan and Nancy Tuana (Albany, NY: State University of New York Press, 2007), 48.

14 Mills, The Racial Contract, 18, emphasis added.

15 Alcoff, "Epistemologies of Ignorance," 47.

16 Applebaum, Being White, Being Good, 39.

17 Jonathan Metzl, Dying of Whiteness: How the Politics of Racial Resentment is Killing America's Heartland (New York: Basic Books, 2019).

18 One may be reluctant to hold poor whites responsible for the plight of racially marginalized populations for multiple reasons. First, poor whites suffer many of the same economic injustices that poor people of color suffer. Second, definitions of whiteness have expanded throughout history to include previously excluded groups. Some whites have therefore also been racially marginalized in the past. Third, holding poor whites responsible for racial injustice may divert attention away from more affluent whites who are disproportionately responsible for severe forms of racial injustice. Given these important considerations, we must be careful to avoid scapegoating poor whites for injustices committed by affluent whites. However, we must also acknowledge the contribution of poor whites to at least some forms of racial injustice. These include the preservation of the status of whiteness in American society and the support for racially oppressive regimes. I thank Kal Alston for this observation.

19 Tommie Shelby, "Ideology, Racism, and Critical Social Theory," The Philosophical Forum 34, no. 2 (2003): 174.

20 Shelby, "Ideology, Racism, and Critical Social Theory," 170-172.

21 Christopher Martin, "Should Deliberative Democratic Inclusion Extend to Children?," Democracy \& Education 26, no. 2 (2018): 8-10.

22 The emphasis on structure and collective responsibility is compatible with notions of individual responsibility. Being ignorant due to no fault of one's own need not release one of their individual responsibility for acting unjust- 
ly as a result of their ignorance. Yet a shift from an individualistic account of responsibility to a structural one must be made with care so as to avoid rendering perpetrators invisible. The purpose is not to exonerate willfully ignorant perpetrators of injustice but rather to assign additional responsibility to all those who facilitate the reproduction of ignorance-the reproduction of ignorance being a fundamental causal factor in the injustice committed by an ignorant perpetrator. I thank Winston Thompson for bringing this problem to my attention.

23 The account of formative epistemic injustice that I present in this paper differs from Martin's in both its scope of consideration and its theoretical foundations. See A. C. Nikolaidis, "A Third Conception of Epistemic Injustice" (working paper).

24 Miranda Fricker, Epistemic Injustice: Power and the Ethics of Knowing (New York: Oxford University Press, 2007), 17-29.

25 Fricker, Epistemic Injustice, 152-161.

26 Dotson, "A Cautionary Tale," 31-35.

27 David Coady, “Two Concepts of Epistemic Injustice," Episteme 7, no. 2 (2010): 102-109.

28 Robbie McClintock, "Formative Justice: The Regulative Principle of Education," Teachers College Record 118, no. 10 (2016): 8-15.

29 McClintock, "Formative Justice," 8-15.

30 Winston C. Thompson, "Rethinking Discussions of Justice in Educational Research: Formative Justice, Educational Liberalism, and Beyond," Teachers College Record 118, no. 10 (2016): 10-13.

31 For a more detailed account of formative epistemic injustice see A. C. Nikolaidis, "What Is the Meaning of Educational Injustice? A Case for Reconceptualizing a Heterogeneous Concept," Philosophy of Education 77 (forthcoming).

32 Elizabeth Anderson, "Epistemic Justice as a Virtue of Social Institutions," Social Epistemology 26, no. 2 (2012): 163-173.

33 One need only consider the extensive research on cognitive biases which demonstrates how humans are often beholden to socially imputed meanings without being readily able to reject them. Our very cognitive dispositions 
render ideology tremendously powerful and constraining to our ability to do justice to our formative capacities and decisions. See Mahzarin R. Banaji and Anthony G. Greenwald, Blindspot: Hidden Biases of Good People (New York: Delacorte Press, 2013); Daniel Kahneman, Thinking Fast and Slow (New York: Farrar, Straus and Giroux, 2011).

34 Pohlhaus and Medina, for instance, discuss how marginally situated knowers understand the world better than dominantly situated knowers because in addition to their own marginalized epistemic resources they are forced to be attentive to dominant epistemic resources. Pohlhaus, "Relational Knowing and Epistemic Injustice," 720-721; Medina, The Epistemology of Resistance, 104-106.

35 Pohlhaus, "Relational Knowing and Epistemic Injustice," 721.

36 Medina, The Epistemology of Resistance, 107-108. 